\title{
EMPREGO DA SUBMUCOSA INTESTINAL SUÍNA EM URETROPLASTIAS COMPLEXAS
}

\author{
THE USE OF PORCINE INTESTINAL SUBMUCOSA FOR COMPLEX \\ URETHROPLASTY
}

\section{Paulo César Rodrigues Palma, TCBC-SP ${ }^{1}$ \\ Cássio Luís Zanettini Riccetto ${ }^{2}$ Marcelo Thiel $^{3}$}

\section{INTRODUÇÃO}

As fístulas uretrocutâneas e as estenoses uretrais pós-operatórias representam as complicações mais freqüentemente relacionadas às uretroplastias. A fístula uretrocutânea resulta, geralmente, da cicatrização deficiente devido à infecção, hematoma ou tensão nas suturas, ou ainda, em decorrência da qualidade tecidual precária, em pacientes submetidos a múltiplas cirurgias.

A submucosa intestinal suína (SIS), após tratamento adequado, resulta numa matriz acelular de fibras colágenas totalmente biocompatível, que tem sido empregada como curativo biológico em lesões cutâneas extensas pós-traumáticas, e mais recentemente, para a confecção de "slings" para o tratamento da incontinência urinária de esforço na mulher.

O objetivo deste trabalho é apresentar o emprego do SIS no tratamento de um paciente com estenose uretral extensa recidivada, associada à uretroplastia pela técnica de Johanson ${ }^{1}$.

\section{RELATO DO CASO}

Paciente portador de balanite xerótica obliterante, submetido previamente a 15 uretrotomias endoscópicas e, inúmeras dilatações uretrais sem estabilização do lúmen uretral. Em virtude da extensão do trajeto estenótico (cerca de $4 \mathrm{~cm}$ ) optou-se pela realização de uretroplastia, segundo a técnica de Johanson ${ }^{1}$. Já no primeiro tempo da cirurgia, durante a incisão do segmento uretral estenótico, constatouse intensa fibrose da uretra peniana e bulbar.

No segundo tempo da uretroplastia, após a introdução de uma sonda de Foley 16 F no neo-meato hipospádico, foram confeccionados retalhos cutâneos paralelos ao platô uretral.

A neo-uretra foi confeccionada a partir dos retalhos obtidos, que foram suturados entre si empregando-se fio de poliglactina 5-0. Em seguida , o SIS foi interposto entre as linhas de sutura da neouretra e, fixado no local com pontos simples de poliglactina 5-0 que foram aplicados em suas extremidades (Figura 1). O procedimento foi finalizado com a realização da meatoplastia e glanduloplastia (Figura 2).

Atualmente o paciente encontra-se com seguimento superior a seis meses, sem evidência clínica e urodinâmica de obstrução infravesical.

\section{DISCUSSÃO}

O SIS corresponde a um novo biomaterial derivado da submucosa de intestino delgado suíno, e consiste de uma matriz extracelular a base de colágeno com poucas células de permeio ${ }^{2}$. Além de oferecer suporte estrutural, possui fatores de crescimento

1. Professor Associado da Disciplina de Urologia da UNICAMP

2. Doutor em Urologia pela UNICAMP

3. Pós-Graduando de Urologia da UNICAMP

Recebido em 26/12/2001

Aceito para publicação em 14/01/2003

Trabalho realizado na Disciplina de Urologia, Faculdade de Ciências Médicas da Universidade Estadual de Campinas, Campinas-SPBrasil. 


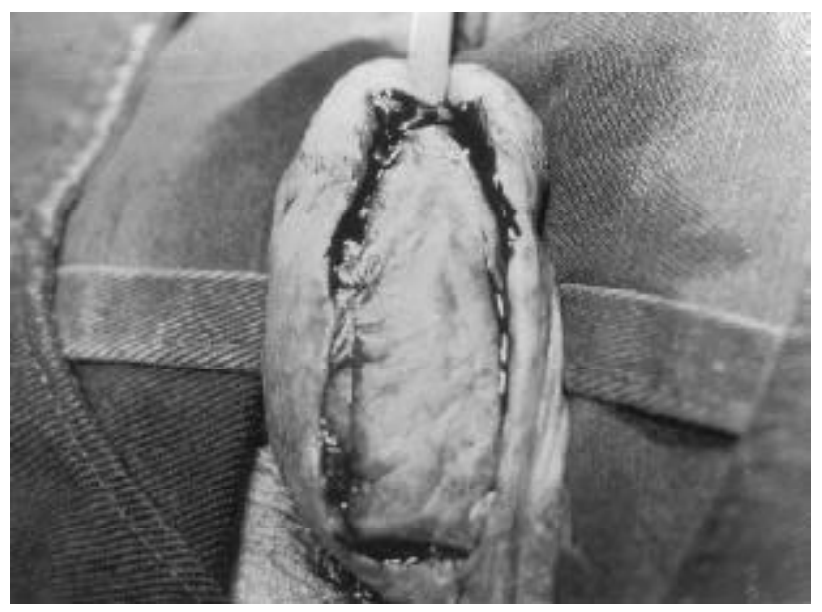

Figura 1 - SIS fixado sobre a linha de sutura da neouretra.

tecidual (TGF-b e FGF-2) com participação ativa no processo de regeneração do tecido sobre o qual é implantado. Em estudos experimentais, o SIS gradualmente incorporou-se ao tecido hospedeiro, e foi substituído, de forma organizada, por ele ${ }^{3}$. Esta regeneração da estrutura do tecido hospedeiro após a implantação foi chamada de "remodelação inteligente" e, aliada ao seu baixo potencial alergênico, difere da maioria dos xenoenxertos propostos até então ${ }^{3}$.

Em estudos experimentais o SIS demonstrou maior resistência à infecção bacteriana, quando com-

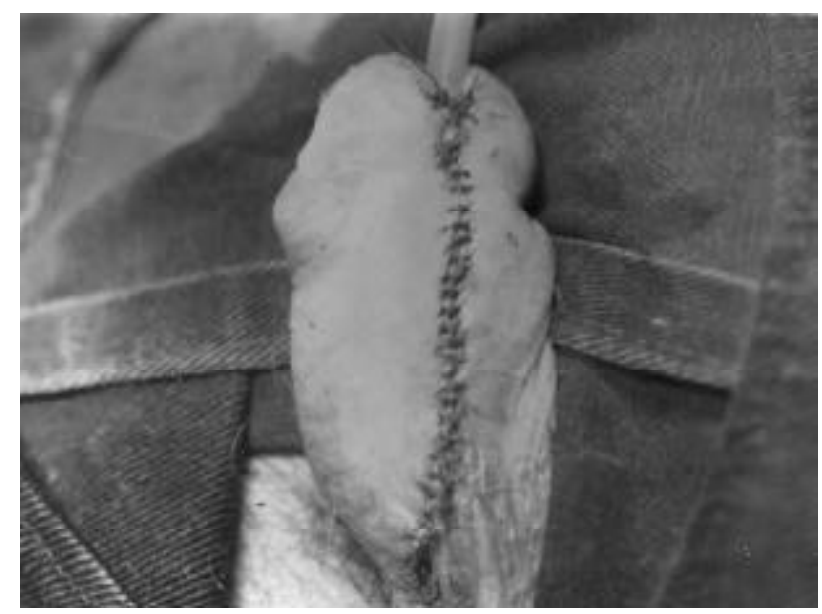

Figura 2 - Aspecto final, após meatoplastia e glanduloplastia.

parado a outros enxertos ${ }^{4}$, o que representa vantagem partircularmente útil nas uretroplastias. Tal resistência pode ser atribuida à rápida neovascularização que se segue ao implante do SIS, e se relaciona ao estímulo local de citoquinas que regulam a angiogênese ${ }^{5}$.

A evolução favorável de um caso complexo de estenose de uretra com a interposição do SIS apresenta uma nova perspectiva a ser explorada nas uretroplastias complexas, sobretudo se estudos prospectivos venham confirmar este resultado.

\begin{abstract}
We report the use of Porcine Intestinal Submucosa (PIS) in association with Johanson technique for urethroplasty, in the treatment of recurring urethral stenosis. The patient had obliterans xerotica balanitis and had previously undergone 15 internal uretotomies as well as various unsuccessful urethral dilations. As a result of stenotic extension, another surgery was planned using Johanson technique. During the first part of the surgery, intense local fibrosis was observed, which required greater care and protection to avoid fistulae formation. PIS was interposed to reduce the chances of the occurrence of this dreaded complication. During the second part of the surgery, a skin flap obtained from tissue parallel to the urethral plateau was used to prepare a neourethra according to the norms of this technique. PIS was fixed at its extremities, and interposed between the neourethral suture and the skin suture to prevent any contact between them. The procedure was completed with the use of meatoplasty and glandulaplasty. After 6month follow up, clinical and urodynamic improvement could be seen. If these results can be confirmed by more extensive studies, PIS will provide new perspectives for complex urethroplasties.
\end{abstract}

Key Words: Urethroplasty; Urethral stricture; Fistula; Intestinal mucosa; Urethra; Surgery. 


\section{REFERÊNCIAS}

1. Johanson $\mathrm{B}-$ Reconstruction of the male urethra in strictures: application of the buried intact epithrlium technic. Acta Chir Scand, 1953,176 (Suppl 1): 3-7.

2. Badylak SF, Lantz GC, Laffey AL et al. - Small intestinal submucosa as a large diameter vascular graft in the dog. J Surg Res, 1989, 47(1):74-80.

3. Prevel CD, Eppley BL, Summerlin DJ et al. - Small intestinal submucosa : utilization for repair of rodent abdominal wall defects. Ann Plast Surg, 1995, 35(4):374380.

4. Badylak SF, Coffey AC, Lantz GC et al. - Comparison of the resistance to infection of intestinal submucosa arterial autografts versus polytetrafluoroethylene arterial protheses in a dog model. J Vasc Surg, 1994, 19(3):465-472.
5. Voytik-Harbin SL, Brightman AO, Kraine MR et al. Identification of extractable growth factors from small intestinal submucosa. J Cell Biochem, 1997, 67(4):478491.

Endereço para correspondência:

Marcelo Thiel

R. Barão de Jaguara, 601 apto 122 Centro

CEP: 13015-001 - Campinas- SP

E-mail:thiel7@uol.com.br

Fone: (19) 3233-4009 ou (19) 9745-6331 